\title{
Grammatical cohesion devices on the Indonesian translation of English bidding document
}

\author{
Widhiya Ninsiana \\ Universitas Sebelas Maret, Surakarta, Indonesia
}

\section{Email address:}

widhiyaninsiana98@gmail.com

\section{To cite this article:}

Widhiya Ninsiana. Grammatical Cohesion Devices on the Indonesian Translation of English Bidding Document. International Journal of Language and Linguistics. Vol. 2, No. 6, 2014, pp. 361-367. doi: 10.11648/j.ijl1.20140206.14

\begin{abstract}
This research studies the grammatical-cohesion devices employed in the Indonesian translation of English bidding documents, 'Dokumen Tender'. This research aims at (1) Finding and describing in details about grammatical-cohesion-marking translation focused on Bidding Document translated as Dokumen Tender. This also describes grammatical cohesion-making translation in which the change thereof is identified, (2) Finding and explaining technique of grammatical cohesion-marking translation which is used by a translator and along with the reason thereof centralized in Bidding Document which is translated into Dokumen Tender, (3) Disclosing and describing in details concerning the meaning equivalence and acceptability of grammatical-cohesion devices in Bidding Document to become Dokumen Tender. This research uses qualitative descriptive approach integrated with established case study and having the orientation on such a product using holistic critical method which examines objective, genetic and affective aspects. The research findings thereof are as follows: First, grammatical cohesion devices in Bidding Documents translated into Dokumen Tender consisting of: First, cohesion marker of reference, substitution, ellipsis and conjunction. There are several grammatical cohesion devices in Bidding Document which experience to change and not to change in cohesion marker. This is because there are differences in grammatical structure, reference, and social culture context. Second, there are 6 kinds of translation techniques, namely literal, amplification, modulation, reduction and linguistic amplification technique. Third, transfer of meaning of cohesion-marking translation in Bidding Document can be deemed good. This is based on the assessments of the experts that $89.77 \%$ of transfer of meaning of cohesion marking translation is considered accurate, $5.61 \%$ is less accurate, and $4.62 \%$ is inaccurate. Acceptability value or worthiness level of cohesion devices in this Bidding Document is stated very good. Worthiness level of cohesion-devices of this Bidding Document reaches $88.12 \%$, and $5.94 \%$ is considered unnatural or improper.
\end{abstract}

Keywords: Translation, Grammatical Cohesion Devices, Acceptability

\section{Introduction}

In this globalization era, interstate relations play an important role especially dealing with global world community environment. At this time, it is not strange and new, if a country builds cooperation with the other country. This is the way by which interstate relation is widely open to perform, not only limited through statehood relationship that is engaged by ambassadors and representatives of the countries, but it is also supported by the existence of a wide range of developments in facilities and infrastructure that support community welfare in certain country. This phenomenon automatically becomes means and ways to perform such interstate relation, which is formalized by the establishment of bilateral or multilateral cooperation.
One of these cooperation, is executed by entering into international tenders which shall be further implemented in the form of cooperation agreement. International tenders set forth in the form of certain agreement made by foreign investors in English must be translated into Indonesian language to comply with the governing laws and regulations in Indonesia.

To translate legal text, in this matter is to translate Bidding Document from English into Indonesian language, to such an extent is not an easy thing. Even legal text translation is more difficult than the other text of translation activities. In translating legal text, a translator in legal field, normally faced the problems from the view of linguistic and non-linguistic". 
Linguistic problems shall include: (a) a very long sentence, (b) terms and 'fixed phrase', (c) expression, and (d) term kerumpangan of terms. While non-linguistic problems may vary, among the other things is the absence of code of ethics [1].

A translator needs a strategy or technique and accuracy in translating a source language text $(\mathrm{BSu})$ into a target language text (BSa) well. Strategy and technique must be undoubtedly mastered by a translator to facilitate her/him to translate from $\mathrm{BSu}$ to BSa text, because normally BSu text has a different grammatical, syntactical and semantic structure. This is caused by each language culture differences.

Cohesion constitutes a language formal aspect in a discourse. This means that cohesion is a 'syntactic organization'. This syntactic organization is a coherently and solidly integrated sentence structure. Cohesion is such a possibility device existing in a language that can make certain 'text' has a unity. This means that the meaning correlation, either lexical or grammatical meaning, shall be necessary to be integrally implemented in the unity of text [2].

This research uses holistic critical approach, which analyzes objective, genetic and affective factors. Genetic factor studied in this research includes grammatical cohesion-marking translation existing in Bidding Document translated into Indonesian language with the title Dokumen Tender, the translation technique used and the study of meaning equivalence and worthiness or acceptability of cohesion-marking translation, reasons or consideration factors underlying a translator in using grammatical cohesion-marking translation technique (affective) and the translation text acceptability (affective aspect).

Bidding Document translation changed into Dokumen Tender as abovementioned indicates the existence of changing cohesion type. For example the following quote:

1.1 At a national level there has been a discrepancy in various aspects and in many regions. To avoid this, the priorities of the national development planning should be identified at the grassroots level (page 7) .

Pada level nasional, ada kesenjangan dalam berbagai aspek di berbagai wilayah (1). Untuk mengatasi semua itu, prioritas-prioritas rencana pembangunan nasional harus dikenalkan mulai dari level akar rumput (Hal.7)

The quote of BSu and BSa texts consists of 2 sentences, namely (1) At a national level......(2) To avoid this.......... In the above sentences, cohesion reference "this" in the sentence (2) $\mathrm{TSu}$ abovementioned in anaphoric way refers to 'discrepancy in various aspects and in many regions' existing in the sentence (1) TSu. Cohesion marker "this" and its reference abovementioned shall be included into no-distance cohesion, because it exists in an adjacent sentence.

In the above translation, cohesion marker "this" is translated 'itu' in sentence (2) TSa. Such "This" translation becomes 'itu' occurs due to change of distance between the speaker and the thing appointed. If cohesion marker "this" should mean that the distance between the speaker and the thing appointed is closed, then, in this translation, cohesion marker 'itu' should have the meaning that distance between the speaker and the thing appointed is far. The translation of "this" to become 'itu' abovementioned is because the cohesion marker "this" is stated by the speaker and the thing appointed by "this" abovementioned, is the discrepancy in various aspects in various areas, it is conceived not closed to the speaker. However, such cohesion-marking translation does not cause the change of reference and the direction of reference. Cohesion marker "this" to become "ini' in the above text is cohesively related.

The quote of such text can be translated into not so different source language text and by not making any contrastive change. Nevertheless, a translator has made a decision to conduct a certain change with plenty of considerations. The occurrence of these changes, particularly cohesion marking change is of course becoming an interesting issue in translation world and it is necessary to be further investigated. Upon the study of holistically and comprehensively varied cohesion marker, it is expected to become a major force in this research.

Research of translation in connection with the cohesion marker as its data source thereof had been conducted by Sri Widyarti Ali in the thesis titled Grammatical and Lexical Cohesion Marker in the short story 'The Killer' written by Ernest Hemingway [3]. She focused her research on grammatical cohesion and lexical cohesion in the short story discourse 'The Killer'. The focus on grammatical cohesion exists in the aspects of reference, substitution, ellipsis and conjunction, while in the lexical aspects there are the aspects of repetition, synonym, hyponym, antonym and meronimi. In the aforesaid thesis, Sri Widyarti Ali did not discuss the quality assessment of its translation based on three aspects, namely accuracy, acceptability and legibility. Another related translation research was conducted by Supana in his dissertation titled Study of Cohesion-marking translation in Novel Wings written by Danielle Steel translated into Indonesian Language. In the aforesaid dissertation, Supana focused his research on cohesion marking changes in novel Wings, translation technique and translation quality of novel Wings in the aspects of accuracy, acceptability and equivalence (holistically). Research regarding cohesion-marking translation had also been carried out by Maja Stanoojevic Gocic, in her article Cohesive Devices in Legal Discourse [4]. In her article, she focused on to cohesion marker in legal text discourse. The aspect studied was grammatical cohesion and lexical cohesion. In discussing legal text cohesion-marking translation, she suggested that someone in drafting contract or in making legal drafting he/she must be careful, in order to avoid any ambiguity in legal text. For example, the use of conjunction 'and' and 'or', potential ambiguity thereof can be conjunctive or disjunctive.

Zainal Arifin in his thesis titled 'Analysis of Reference Cohesion-marking translation in the Book of Civic Culture written by Gabriel A. Almond Politic and Sydney Verba to become Political Culture by Sahat Simamora [5]. The research conducted by Zainal Arifin was limited to the reference cohesion marking study only. The other types of cohesions, namely substitution, ellipsis and conjunction and lexical 
cohesion marker are not studied in this research. Study of cohesion-marking translation from English to the other languages, other than Indonesian language, among the other things were carried out by Li Xiuying in her article titled An analysis of the Cohesive Devices Adopted by Burton Watson and William H. Nienhauser, J.R. in Translating Shi Ji (Records of the Historian) Into English [6]. In this article it is discussed text cohesion-marking translation in Chinese language titled 'Shi ji' into English by two translators, namely Burton Watson and William H. Nienhauser, J.R. The Cohesion marker Studied were only the cohesion markers of reference and conjunction. Reference cohesion marker in 'Shi ji' text, is normally made ellipsis. For example if there are two the same persons in the conjunctional clauses, then, that person are only mentioned in the first clause, in the following clauses, such person' name is ellipsis. Burton Watson in his translation more explicitly emphasized such cohesion marker than William $\mathrm{H}$. Nienhauser, J.R. Meanwhile, conjunction in the 'Shi ji' text was often made ellipsis, but it was made explicit by the two translators.

The next study, was carried out by Saedi, in an article titled "Lexical Cohesion and Translation Equivalence" [7]. In this article, it is expressed that cohesion is one of very important text features. As one of text features, cohesion shall be able to distinguish between text and non-text. In discussing lexical cohesion equivalence, it must first understand lexical strategy applied in a BSu text and semantic structure types in a cohesive lexical meaning in a BSu text. After which, BSa text in its lexical cohesion strategy and semantic structure is accordingly studied. If $\mathrm{BSu}$ and $\mathrm{BSa}$ texts have the same lexical cohesion strategies, then, $\mathrm{BSu}$ and $\mathrm{BSa}$ texts considered commensurate. In this article, it is not stated concerning BSu and BSa texts analysis as the counterpart, but it is only stated about BSu text and its lexical cohesion analysis thereof.

Based on several previous translation researches as mentioned hereinabove, then, the difference of this research and the previous researches, briefly, the gap between this research and the previous researches can be formulated as: (1) grammatical cohesion-marking translation in Bidding Document translated into Indonesian language 'Dokumen Tender'? In this issue it is disclosed grammatical cohesion-marking translation experiencing to change or not, (2) technique of grammatical cohesion-marking translation, (3) meaning equivalence and translation acceptability of grammatical cohesion marker; (4) readers' response in legibility level, and (5) grammatical cohesion marker's impact, translation technique, equivalence level, acceptability and legibility techniques towards the quality of Bidding Document translation result to become 'Dokumen Tender?'

Issue in this research can be formulated as follows: (1) How is grammatical cohesion-marking translation in Bidding Document translated into Indonesian language, Dokumen Tender? This issue discloses grammatical cohesion-marking translation experiencing to change or not to change; (2) What technique of grammatical cohesion translation is used by a translator and his/her reasons in Bidding Document translation to become Dokumen Tender? (3) How is the meaning equivalence and acceptability of grammatical cohesion-marking translation in Bidding Document translation to become Dokumen Tender?

Based on such research issues, then, objectives of this research are as follows: (1) To find and to describe in details, grammatical cohesion-marking translation in Bidding Document translation to become Dokumen Tender. It is also disclose concerning grammatical cohesion-marking translation that is having changes or not having changes; (2) To find and to explain the technique of grammatical cohesion-marking translation used by a translator and his/her reasons in Bidding Document translatiorn to become Dokumen Tender?; (3) To disclose and to describe in details the meaning equivalence and the acceptability of grammatical cohesion-marking translation in Bidding Document translation to become Dokumen Tender.

\section{Method}

This research is a qualitative research by using holistic critical approach and in the form of case study with established single case. This research is holistic in nature, namely a research that covers genetic, objective and affective aspects. Genetic aspect refers to a translator, a person that produces translation creation [8]. Objective aspect relates to translation creation as its study object. Objective of research study oriented to the product to which assessment level of translation quality is forcefully required, either from message accuracy level, legibility level, or its translation text acceptability, while to determine a translation quality thereof, the readers' responses shall be become one important aspects that determine a successful translation (affective aspect).

Objective aspect in this research is in the form of study concerning technique of grammatical cohesion-marking translation, meaning equivalence and acceptability of grammatical cohesion-marking translation. The underlying reasons are genetic aspects. Meanwhile, affective reasons of these reasons are in the form of text readers, particularly grammatical cohesion-marking translation in this Bidding Document.

Object of this research is grammatical cohesion-marking translation in Bidding Document translation into Indonesian language "Dokumen Tender". This Bidding Document is the cooperation contract document entered into between LIPI Bogor and Spain Government in 2008

Data of this research is a written data in the form of 1) grammatical cohesion marker in Bidding Document and its translation in Indonesian language "Dokumen Tender"; 2) technique of grammatical cohesion-marking translation; 3) information concerning the readers' responses in Bidding Document translation, particularly in the form of meaning equivalence, acceptability and its text legibility.

Data source used in this research are (1). Bidding Document in English language and translated into Indonesian language titled Dokumen Tender; (2) Informants consist of (a). Rater, consisting of 6 raters to assess three translation quality 
assessment aspects that includes accuracy and acceptability. Sample in this research is Bidding Document. Sampling of resource person of this research is translation experts, linguistic experts, particularly in the field of discourse, legal experts as well as translation legal text readers. Technique of data collection is conducted by means of listen and note technique or document analysis/content analysis [9].

Questionnaire in this research is open-ended questionnaire. Questionnaire in this research is used to collect the meaning equivalence grade data of cohesion-marking translation, acceptability of grammatical cohesion-marking translation, and translation legibility.

In this research, the researcher conducted interview with a translator who produces Bidding Document translation to obtain the information needed. Technique of such interview was also applied to linguistic experts in the field of discourse and linguistic expert in the field of translation. This interview was conducted to confirm and to explore the data obtained through the questionnaire which has previously been filled out by the aforementioned experts.

Technique of data validity used in the research is data source and method triangulation. In this source triangulation, document analysis result will be compared to questionnaire and interview results. While data validity checking in the method triangulation is conducted by the various data collection techniques which includes document analysis, questionnaire and in-depth-interview.

Data analysis technique used in this research is to study document and archives (content analysis). This technique is conducted by way of reading and recording technique. The technique of recording document (content analysis) is the way to find various thing in accordance with the research's needs and objectives. While its data analysis stages it uses ethnographic analysis stage proposed by Spradley namely (1) domain analysis, (2) taxonomic analysis, (3) compensational analysis, and (4) cultural theme analysis.

\section{Research Findings and Discussion}

\subsection{Research Findings}

\subsubsection{Grammatical Cohesion-Marking Translation}

After going through several analysis stages, by applying taxonomic analysis technique suggested by Spradley, in ethnographic method, it is found that data containing grammatical cohesion elements demonstrated in the use of word, phrase, clause, and sentence [10]. In general, grammatical cohesion marker is divided into four parts, namely, reference, substitution, ellipsis, and conjunction. As for grammatical cohesion marker in Bidding Document it shall be person reference cohesion markers namely 'he, him, they, their, our, it and its; demonstrative reference markers, namely this, these, those, the; nominal substitution cohesion markers namely 'one and ones'; verbal substitution markers namely 'done'; conjunction grammatical cohesion marker namely and, or, thus, after, before, first, second, third, furthermore, however, but, otherwise, in addition, and therefore.

Cohesion-marking translation and technique of grammatical cohesion-marking translation in Bidding Document, some of which experience to change and some of which does not experience to change.

\subsubsection{Technique of Grammatical Cohesion Marker}

In overall, there are six kinds of techniques used by translator in translating grammatical cohesion marker, namely, (1) literally, (2) modulation, (3) reduction, (4) amplification, (5) transposition amplification, and (6) linguistic amplification. Domination of use of these six kinds of techniques are conducted by translator with various considerations and certain reasons. As for the 6 main reasons proposed by translator in using these techniques are namely: (1) to prioritize meaning, (2) to make confirmation, (3) to adjust to Bsa social culture, (4) to make variation, (5) to avoid meaning ambiguity, and (6) easy to be understood. Total grammatical cohesion-marking translation under the reason to prioritize meaning is namely $45(44.56 \%)$. Total reasons for the second translation, namely the reasons to make confirmation are $18(17.82 \%)$, reasons to adjust to BSa social culture are $16(15.84 \%)$, reason to make variation are 8 (7.92\%), to avoid meaning ambiguity are $7(6.93 \%)$ and reason in order to be easily understood are 7 (6.93\%).

Grammatical cohesion-marking translation under the reason to prioritize meaning ( 45 or $44.56 \%$ ) is conducted by translator by using literally, amplification, transposition amplification translation technique, and modulation translation technique. The reason of cohesion-marking translation to make confirmation (18 data or $17.82 \%$ ) is conducted by using literally, amplification, transposition amplification, reduction and modulation translation techniques. Cohesion marker the translation of which is conducted under the reason to adjust to BSa social culture (16 data or $15.84 \%$ ) is conducted by modulation, amplification, literally, transposition amplification and linguistic amplification techniques. Cohesion-marking translation conducted under the reason to make variation ( 8 data or $7.92 \%$ ) is conducted by using modulation, literally and amplification translation techniques. The reason to avoid meaning ambiguity ( 7 data or $6.93 \%$ ) is reached by using three kinds of techniques, namely reduction, amplification and modulation. Meanwhile, the reason of cohesion-marking translation in order to be easily understood ( 7 data or $6.93 \%$ ) is conducted by using four kinds of techniques, namely amplification, literally, transposition and modification techniques.

Literally translation technique, under the reason to prioritize meaning, is used for, reason to make confirmation: $11(10.89 \%)$, the reason to adjust to BSa social culture: 3 $(2.97 \%)$, the reason to make variation: $2(1.8 \%)$, and the reason to be easily understood: 2 (1.98\%). Amplification technique is used for six techniques. Amplification technique in the purpose of prioritizing the meaning is $5(4.95 \%)$, to make confirmation is $3(2.97 \%)$, to adjust to BSa social culture is $4(3.96 \%)$, to make variation is $1(0.99 \%)$, to avoid meaning ambiguity is $1(0.99 \%)$ and in order to be easily understood is 
$3(2.97 \%)$. Meanwhile for modulation technique it is used for six reasons namely the reason to prioritize meaning are 3 $(2.97 \%)$, to make confirmation is $1(0.99 \%)$, to adjust to BSa social culture are 6 data $(5.94 \%)$, to make variation is 5 $(4.95 \%)$, to avoid ambiguity is $1(0.99 \%)$, and in order to be easily understood is $1(0.99 \%)$. Transposition amplification technique in cohesion-marking translation is used for four reasons namely to prioritize meaning: $4(3.96 \%)$, to make confirmation: $1(0.99 \%)$, to adjust to BSa social culture: 2 data $(1.98 \%)$, and to be easily understood: $1(0.99 \%)$. Reduction technique in cohesion-marking translation is used for two reasons, namely to make confirmation and to avoid meaning ambiguity. For the reasons to make confirmation there are 2 data $(1.98 \%)$, and for the reason to avoid meaning ambiguity there are 5 data (4.95\%). Linguistic amplification technique in cohesion-marking translation is only used just for one reason, namely to adjust to $\mathrm{BSa}$ social culture, that is only 1 data $(0.99 \%)$.

\subsubsection{Meaning Equivalence and Acceptability of Grammatical Cohesion-Marking Translation}

For meaning equivalence of grammatical cohesion marker, Expert 1 gave score 3 for 92 data (91.09\%). Expert 2 gave 3 to 90 data $(89.11 \%)$, while expert 3 gave score 3 to 90 data $(89.77 \%)$. The average amount for score 3 by the three experts are as much as 90,67 or $89.77 \%$. This indicates that the accuracy of meaning transfer of cohesion-marking translation in Bidding Document translation is quite high. The three experts agree to give score 3 to 84 data or $83.17 \%$. This indicates that meaning transfer of grammatical cohesion marker in total of 84 data as mentioned hereinabove, are considered accurate according to the 3 experts, the three experts gave score 2 and agree to 1 data $(0.99 \%)$, and gave score 1 to 3 data $(2.97 \%)$. The difference on such number of data does not mean that the meaning transfer in such grammatical cohesion translation has been failed. On the above exposure, most parts of meaning transfer have been transferred well, and the meaning is delivered wholly. This can be seen from the average score which reaches 90.67 pieces or $89.77 \%$.

While for acceptability of grammatical cohesion-marking translation, Expert 1 gave score 3 to 91 data (90.10\%), almost the same assessment was given by expert 2 , namely to give score 3 to 88 data $(87.13 \%$ ), while expert 3 gave score 3 to 88 data $(88.13 \%)$ of the total data assessed. As for the average score 3 given by these three experts is $89(88.12 \%)$. This means that acceptability level of grammatical cohesion-marking translation in Bidding Document is excellent. The experts agree to give score 3 to 79 data (78.22\%). The data agreed by all experts for score 2 is only 1 data or $(0.99 \%)$, there is no score 1 which is not agreed by the three experts. Percentage of average score of grammatical cohesion marker considered reasonable by these three experts reaches 89 pieces or $88.12 \%$. This means that reasonability of grammatical cohesion-marking translation in Dokumen Tender is excellent.

\subsection{Discussion}

\subsubsection{Grammatical Cohesion Marker}

Difference of inter-language grammatical system will be implemented in the chain to mark cohesion in BSu and BSa. The change of cohesion marker in translation may affect the meaning changes [11]. The change of cohesion marker in Bidding Document translation cannot also be separated from the change of meaning. Demand of deformation in translation in order that TSa is in conformity with the target language principle (BSa) shall occur in Bidding Document translation reflecting in the change of grammatical cohesion marker between both of them. In such Bidding Document, the change of grammatical cohesion marker, some of which experience to change and the some of which does not experience to change. This is due to the existence of any grammatical structure differences, difference of reference, and difference of social culture context. The change of grammatical cohesion marker will also affect translation quality, particularly to equivalence level thereof.

\subsubsection{Technique of Gramatical Cohesion Marker}

Different translation techniques are applied to each type of grammatical cohesion marker. Translation technique the variations of which are the same from to another shall be the reference and conjunction cohesion markers. To translate reference cohesion marker there are 5 kinds of of techniques used, namely: 1) literally, 2) amplification, 3) transposition amplification, 4) modulation, and 5) reduction. Translation technique of conjunction cohesion marker is 1) literally, 2) amplification, 3) transposition amplification, 4) modulation, and 5) linguistic amplification. Meanwhile, substitution cohesion marker uses 3 kinds of techniques, namely 1) amplification, 2) transposition amplification, and 3) reduction.

Such translation technique has different percentage of score, which affect the change of meaning, acceptability and legibility. The highest percentage is placed by reduction technique, which reaches $71.43 \%$. However, all cohesion-marking translation by adopting such reduction technique is acceptable and the translation text thereof is easy to be understood.

The most used translation technique is literally translation technique, which reaches 50 data or $(49.51 \%)$. 1 data $(2 \%)$ among the 50 data translated by using such literally technique abovementioned experiences to get the shift of meaning. Cohesion marker translated by using amplification technique reaches 18 data $(50 \%)$, and it causes the change of meaning. The change of meaning caused by such modulation technique reaches $16.83 \%$. Subsequently, translation technique causes the occurrence of change of meaning is amplification technique and transposition as well ( 8 data or $25 \%$ ). Reduction technique causing the change of meaning is as many as 7 data. Such all seven data experience the change of meaning (100\%). From the abovementioned description, it appears that the use of grammatical cohesion marker technique has the effect on the meaning equivalence, acceptability and translation text legibility. The translation techniques which mostly experience to get change are reduction technique and modulation 
technique. Even though, the use of this reduction and modulation technique is causing the shift of meaning and lack of translation acceptability, but such techniques shall have high legibility level. This shows that the use of such three aspects indicated in Bidding Document translation quality, namely the equivalence of meaning, acceptability and legibility are not well-maintained.

\subsubsection{Equivalence and Acceptability to Translation Quality}

Assessment for equivalence level to Bidding Document was given by the three experts to 101 data of grammatical cohesion-marking translation. By virtue of these three experts assessments, the meaning equivalence and reasonability are accordingly identified. This experts gave the assessment of agree and disagree to such 101 data. Score of agree (score 3) means the meaning transfer is accurate to all grammatical cohesion marker, score 2 means the meaning transfer of grammatical cohesion marker is less accurate, and score 1 considered that the meaning transfer is not accurate.

As for the detail description of the three assessment undertaken by these three experts are as follows: Expert 1 gave score 3 to 92 data $(91.09 \%)$. Expert 2 gave score 3 to 90 data $(89.11 \%)$, while expert 3 gave score 3 to 90 data $(89.77 \%)$. Total average for score 3 by such three experts are as much as 90.67 or $(89.77 \%)$. This shows that the score 90.67 or $(89,77 \%)$ as mentioned hereinabove, the meaning transfer to grammatical cohesion marker are considered accurate or equivalent.

Meanwhile, for score 2 given by such three experts are namely expert 1 as many as 1 data $(0.99 \%)$, expert 2 as many as 8 data $(7.92 \%)$ and expert 3 as many as 8 data $(7.92 \%)$. Average score 2 given by such three experts is 5.67 or $(5.61 \%)$. Average score given by those three experts shows that the transfer of meaning is less accurate. While the remaining average of score 1 given by these three experts of 4.67 or $(4.62 \%)$ is stated inaccurate. Inaccuracy of this grammatical cohesion-marking translation is in relation to the change of grammatical cohesion marker conducted by translator.

Assessment over the reasonability of the use of translation language by three experts namely linguistic expert, legal expert and Indonesian language expert. Each expert respectively gave score 3 for reasonability assessment of translation language as follows: (1) frequency of data 91 or $90.10 \%$ (expert 1). (2) frequency of data 88 or $87.13 \%$ (expert 2) and (3) frequency of data 88 or $87.13 \%$ (expert 3). Average score 3 given by the three experts is 89 or $88.13 \%$, this indicates that grammatical cohesion-marking translation has considered reasonable. Furthermore for score 2 given by experts to grammatical cohesion-marking translation is different from one another. The granting of score 2 means that grammatical cohesion-marking translation is less acceptable. Expert 1 gave assessment for score 2 to 1 data (0.99\%), expert 2 to 8 data $(7.92 \%)$, and for expert 3 gave score 2 to 9 data $(8.91 \%)$. Average score 2 given by such three experts is 6 or $5.94 \%$. The abovementioned findings shows that the average score given by the experts to translation considered acceptable reaches $79.21 \%$, and less acceptable translation only reaches
$20.79 \%$. Percentage of reasonability score to this Bidding Document is considered "fair" than the percentage of equivalence score.

\section{Conclusion}

From data analysis and discussion, it can be undoubtedly concluded several matters as follows: First, grammatical cohesion marker in Bidding Document consists of: reference cohesion marker, substitution, ellipsis and conjunction. Upon such Bidding Document, some grammatical cohesion marker will experience to change and some of which will not. This is due to the existence of grammatical structure difference, difference of reference, and difference of social culture context. Demand of deformation in translation in order that $\mathrm{TSa}$ is in conformity with the target language principles (BSa) shall occur in Bidding Document translation which is reflected in the change of grammatical cohesion marker between both of them. The existence of difference between BSu and BSa shall cause the change in grammatical cohesion-marking translation. This changes some of which are mandatory in nature and the others are optional. Mandatory change shall be the change which must be conducted due to the existence of $\mathrm{BSu}$ and BSa different system. The Change of grammatical cohesion marker caused by the difference of grammatical structure, such as the difference of grammatical structure of $\mathrm{BSu}$ nominal group which is generally defined by 'pre-modifier', while BSa is determined by 'post-modifier'. This difference shall cause the change of cohesion marker change, particularly in substitution cohesion making translation. the Difference of reference occurs in the difference of personal system which affect this cohesion marker's change. The difference of single $\mathrm{O} 3$ cohesion marker in BSu and BSa may result in the ambiguity in translation. To avoid this ambiguity, a translator uses reduction technique. By using reduction technique, the difference of personal system in $\mathrm{BSu}$ and BSa can be anticipated, such as the use of pronouns 'they' as personal reference cohesion marker to become ellipsis lexical cohesion marker. Thereafter, the difference of social culture context thereof with respect to the difference of conjunction in $\mathrm{BSu}$ and $\mathrm{BSa}$ can be further addressed. Conjunction cohesion marker 'in addition' constitutes an additive cohesion marker. The Difference of 'in addition' conjunction in $\mathrm{BSu}$ and $\mathrm{BSa}$ is performed by using modulation technique. The use of modulation technique performed by translator is to adjust to social culture context $\mathrm{TSa}$, namely in order that the information in TSa is properly conveyed.

Second, that out of 18 kinds of translation techniques proposed by Molina and Albir [12], but there are only 6 translation techniques used, namely translation technique of literally, amplification, modulation, transposition amplification, reduction and linguistic amplification technique. There are 6 translation reasons in using such 6 techniques, namely 1) to prioritize the meaning, 2) to make confirmation, 3) to adjust to BSa social culture, 4) to make variation, 5) to avoid meaning ambiguity, and 6) in order to be easily understood. Translation using those 6 translation 
techniques aim at conforming that the translation result of which shall be easy to be understood as Indonesian language original text, it is not like translation text. The Usage of the above range of reasons also shows that translator is not just concerned to the meaning context, but he/she must also take into account the reasonability and the legibility aspect of the text.

Third, the change in cohesion-marking translation in Bidding Document text may affect the meaning equivalence. Bidding Document text's cohesion-marking translation can be stated quite high. This is based on the experts' assessment that $89.77 \%$ of the transfer of cohesion marker is considered inaccurate, it means that the transfer of cohesion-marking translation that is considered less accurate is as much as $5.61 \%$, and $4.62 \%$ is considered inaccurate. Acceptability score or reasonability level of cohesion-marking translation in Bidding Document text is stated excellent. Score of reasonability level in cohesion-marking translation of this Bidding Document text reaches $88.12 \%$ and $5.94 \%$ is considered unnatural or not reasonable.

Fourth, in overall quality score obtained for Bidding Document to become Dokumen Tender is $89.77 \%$, the transfer of cohesion marker meaning is considered accurate, and reasonability level score is stated good. While legibility level is fair. Grammatical cohesion-marking translation in Bidding Document has been translated accurately into the target language.

\section{References}

[1] Rochayah, Machali. 2005. Masalah Kebahasaan dan Non-kebahasaaan dalam Penerjemahan Teks Hukum. Yogyakarta:Universitas Negeri Yogyakarta.
[2] Halliday, M.A.K \& Ruqaiya Hasan. 1976. Cohesion in English. London: Longman House

[3] Sri Widyarti. 2012. Penanda Kohesi Gramatikal dan Leksikal Dalam Cerpen “The Killers' Karya Ernest Hemingway. Tesis. Surakarta : UNS

[4] Gocic, Maja Stanojevic. 2012. Cohesive Devices in Legal Discource. Dalam Jurnal Linguistics and Literature. Vol.10 No.2.2012.pp.89-98

[5] Zainal Arifin. 2006. Analisis Terjemahan Penanda Kohesi Rujukan dalam Buku Civic Culture Karya Gabriel A. Almond Politik dan Sydney Verba menjadi Budaya Politik oleh Sahat Simamora. Tesis: Universitas Sebelas Maret

[6] Li Xiuying. 2009. "An analysis of the Cohesive Devices Adopted by Burton Watson and William H. Nienhauser, J.R. in Translating Shi Ji (Records of the Historian) Into English". url:http//accurapid.com/jouurnal/28.edu/htm

[7] Saedi, K.Lotfipour. 1997. Lexical Cohesion and Translation Equivalence. Meta : Translators Journal. Vo. 42.1997

[8] Nababan. 2007. Aspek Genetik, Objektif dan efektif dalam penilalian Kualitas Terjemahan.Artikel Publikasi Ilmiah Penelitian Hibah Kompetensi. Surakarta: Universitas Sebelas Maret Surakarta. Linguistika. Jurnal. Vol.14.No.26

[9] Burns, A. 1999. Collaborative Action Research for English Language Teachers. Cambridge : Cambridge University Press

[10] Sparley. James, P. 1997. Metode Etnografi. Yogyakarta: Tiara Wacana Yogya

[11] Venuti, L.ed (2000). The Translation Studies Reader (Edition 2) New York: Roudledge

[12] Molina, L \& Albir, A.H. 2002. Translation Technique Revised : a Dynamic and Functionalist Approach. Meta : Translators Journal. Vol. XLVII, No.4 